\title{
Enhanced lipid and biomass production by a newly isolated and identified marine microalga
}

\author{
Mouna Dammak', Sandra Mareike Haase ${ }^{2}$, Ramzi Miladi ${ }^{1}$, Faten Ben Amor ${ }^{1}$, Mohamed Barkallah ${ }^{1}$, David Gosset ${ }^{3}$, \\ Chantal Pichon ${ }^{3}$, Bernhard Huchzermeyer ${ }^{4}$, Imen Fendri ${ }^{5}$, Michel Denis ${ }^{6}$ and Slim Abdelkafi ${ }^{*}$
}

\begin{abstract}
Background: The increasing demand for microalgae lipids as an alternative to fish has encouraged researchers to explore oleaginous microalgae for food uses. In this context, optimization of growth and lipid production by the marine oleaginous $V_{2}$-strain-microalgae is of great interest as it contains large amounts of mono-unsaturated (MUFAs) and poly-unsaturated fatty acids (PUFAs).
\end{abstract}

Methods: In this study, the isolated $V_{2}$ strain was identified based on $23 S$ rRNA gene. Growth and lipid production conditions were optimized by using the response surface methodology in order to maximize its cell growth and lipid content that was quantified by both flow cytometry and the gravimetric method. The intracellular lipid bodies were detected after staining with Nile red by epifluorescence microscopy. The fatty acid profile of optimal culture conditions was determined by gas chromatography coupled to a flame ionization detector.

Results: The phenotypic and phylogenetic analyses showed that the strain $V_{2}$ was affiliated to Tetraselmis genus. The marine microalga is known as an interesting oleaginous species according to its high lipid production and its fatty acid composition. The optimization process showed that maximum cell abundance was achieved under the following conditions: $\mathrm{pH}$ : 7, salinity: 30 and photosynthetic light intensity (PAR): $133 \mu \mathrm{mol}$ photons. $\mathrm{m}^{-2} \cdot \mathrm{s}^{-1}$. In addition, the highest lipid content ( $49 \pm 2.1 \%$ dry weight) was obtained at $\mathrm{pH}: 7$, salinity: 37.23 and photosynthetic light intensity (PAR): $188 \mu \mathrm{mol}$ photons. $\mathrm{m}^{-2} \cdot \mathrm{s}^{-1}$. The fatty acid profile revealed the presence of $39.2 \%$ and $16.1 \%$ of total fatty acids of mono-unsaturated fatty acids (MUFAs) and poly-unsaturated fatty acids (PUFAs), respectively. Omega $3(\omega 3)$, omega $6(\omega 6)$ and omega $9(\omega 9)$ represented 5.28\%, 8.12\% and 32.8\% of total fatty acids, respectively.

Conclusions: This study showed the successful optimization of salinity, light intensity and pH for highest growth, lipid production and a good fatty acid composition, making strain $V_{2}$ highly suitable for food and nutraceutical applications.

Keywords: Microalgae, Tetraselmis sp., Response surface methodology, Lipids, Flow cytometry, Poly-unsaturated fatty acids

\section{Background}

Marine photosynthetic microalgae are potential producers of various bioactive substances such as vitamins [1], pigments [2, 3], poly-unsaturated fatty acids (PUFAs) $[2,4]$, triglycerides [5] and polysaccharides [6]. In fact, the marine oleaginous microalgae have been used in food and nutraceutical applications $[7,8]$ as a great source and producers of good lipids and PUFAs such as

\footnotetext{
* Correspondence: slim.abdelkafi@enis.tn

${ }^{1}$ Biotechnologie des Algues, Biological Engineering Department, National

School of Engineers of Sfax, University of Sfax, Sfax, Tunisia

Full list of author information is available at the end of the article
}

omega 3 (EPA (C20:5), DHA (C22:6), $\alpha$-Linolenic (C18:3 $(n-3)))$, omega 6 (C18:2), $\gamma$-Linolenic (C18:3 (n-6)) which are very important for human health and treatment of disease such as cancer, Alzheimer's, modulatory vascular resistance, atherosclerosis and infant malnutrition [9]. Microalgae species generate some natural adaptation mechanisms under several, even noxious, culture conditions. These mechanisms induced modifications in their biochemical composition, like changing intracellular fatty acid biosynthesis as a protection against osmotic stress resulting from salinity changes [10]. Many researches conducted on lipid metabolism showed that 
several factors could affect lipid biosynthesis and their accumulation in microalgae, such as high light intensity [11-13], high salinity [14, 15], nitrogen and phosphorus starvation $[16,17]$, temperature [18-20] and $\mathrm{pH}[21]$. In fact, light intensity and salinity are major environmental factors that affect photosynthesis and enzymatic activities. Some findings demonstrated that tuning light intensity alone could increase lipid content in green microalgae. Evidence was also reported for lipid production increase at low pH (6) [21]. However, the combined effects of environmental factors on lipid biosynthesis by green microalgae remained poorly documented. Microalgae cells have to reduce free radical synthesis under stressful culture-conditions by inhibiting electron accumulation in thylacoid membranes [22]. Under high-light-intensity stress, the induction of the enzyme pathway for carbon fixation was associated with a high electron flux [11]. Consequently, carbon fixation resulted in producing a triose phosphate as a primary product that can be involved in lipid or starch biosynthesis [22]. Salinity stress can lead to decrease or stop microalgal growth, biomass production and conversion of photosynthetic energy to chemical energy for fatty acid and starch synthesis [10]. According to Rodolfi et al. [23] and Studt [24], green microalgae cultures can produce oil with a yield 5 to 20 times that of common plant under stress culture conditions $[25,26]$.

Among 30000 strains that have been isolated and identified [27], the green marine microalgae Tetraselmis sp. (Chlorophyta) was selected as a model strain that is able to grow under several culture conditions due to the following criteria: its photosynthetic pathway versatility, its important nutritional value (lipids, pigments, etc.) and lack of toxicity $[28,29]$. It was reported by Mata et al. [30] that Tetraselmis sp. was the most known microalgae that produce high lipid content. In fact, lipid composition of Tetraselmis sp. was strongly modified by culture conditions $[11,31]$. Thus, this species is considered to be an essential source of PUFAs, especially eicosapentaenoic acid (EPA) [32]. According to Huang et al. [33], total lipid content of microalgae Tetraselmis subcordiformis reached up $33.72 \%$ of dry weight (DW) when it was cultivated in presence of $1.2 \mathrm{mM}$ ferric ion. Marine green microalgae species such as Nannochloropsis sp. produced a total lipid content of more than $47 \%$ DW when cultivated at optimal temperature, salinity and light intensity [10]. In this study, the marine green microalga Tetraselmis sp. suitable to lipid production was isolated and identified based on $23 \mathrm{~S}$ rRNA gene. Response surface methodology (RSM) coupled to Box-Behnken design (BBD) was applied to optimize responses and to analyse the effect of environmental factors and their interactions. The enhancement of lipid content upon tuning environmental conditions was monitored by gravimetric method and flow cytometry (FCM) after staining cells with Nile red (NR), a lipophilic fluorescent probe NR [34, 35] and the lipid bodies were observed by epifluorescence microscopy. To our knowledge, the analysis of lipid accumulation by flow cytometry (FCM) after staining with NR in Tetraselmis species isolated from the Mediterranean Sea was not reported up to now. Statistical methods were applied to develop low cost culture systems and to achieve maximum cells abundance and lipid production by this strain.

\section{Methods \\ Isolation, purification and molecular identification of microalgal strains \\ Enriched cultures}

Seawater samples were collected at the Tunisian Coast of Sidi Mansour (Mediterranean Sea). Samples $\left(200 \mathrm{~cm}^{3}\right)$ were first passed through a $60 \mu \mathrm{m}$ pore size membrane to remove protozoa. Then, the filtered seawater was passed successively through 3 membranes with $20.0,0.4$ and $0.22 \mu \mathrm{m}$ pore size, respectively. Thereafter, $2 \mathrm{~cm}^{3}$ of the final filtrate were transferred into sterile tubes and each membrane was immersed into a $250 \mathrm{~cm}^{3}$ flask containing $50 \mathrm{~cm}^{3}$ of F/2 Provasoli medium [36]. Every 3 days, the flasks and tubes were examined and the algal growth was monitored by inverted microscopy (Motic microscope AE2000, Spain) at 40× magnification.

\section{Isolation of microalgae}

After initial cultivation of the samples with F/2 medium, pure cultures were isolated by performing serial dilutions, plating and by the use of micromanipulation methods. Individual colonies were routinely maintained on both liquid and agar slants of F/2 medium by regular sub-culturing for 15 days and regularly examined by microscopy.

\section{Cultivation}

Cultures of $\mathrm{V}_{2}$ strain were maintained in $250 \mathrm{~cm}^{3}$ Erlenmeyer flasks containing $150 \mathrm{~cm}^{3}$ seawater complemented with $\mathrm{F} / 2$ medium $(\mathrm{pH} 7)$ at $25{ }^{\circ} \mathrm{C}$ and continuously illuminated at a photosynthetic light intensity (PAR) of approximately $84 \mu \mathrm{mol}$ photons. $\mathrm{m}^{-2} \cdot \mathrm{s}^{-1}$ (TL5 tungsten filament lamps; Philips Co., Taipei, Taiwan), except for the medium and high (133 and $182 \mu \mathrm{mol}$ photons. $\mathrm{m}^{-2} \cdot \mathrm{s}^{-1}$, respectively) irradiance experiments. All the cultures were initiated by supplementing the $F / 2$ medium with $10 \%(\mathrm{v} / \mathrm{v})$ inoculum (concentration of algal stock cultures) and incubated for 15 days.

\section{DNA isolation, sequencing and phylogenetic analysis}

Genomic DNA was extracted by a chloroform/isopropanol method from $10 \mathrm{~cm}^{3}$ of algae suspension that was sedimented by centrifugation at $4500 \times g$ for $10 \mathrm{~min}$. The algal suspension was collected at the end of the exponential phase of the related culture [2] as described in Haase et al. [37]. Two primers, namely, p23SrV_f1 (5' 
GGA CAG AAAGAC CCT ATG AA 3') and p23SrV_r1 (5' TCA GCCTGT TAT CCC TAG AG 3') were used for Phusion PCR reaction [37]. The 23S region [38] of the DNA gene sequence was determined by Seqlab, Germany and the blast from the National Centre for Biotechnology Information (NCBI) was used to compare nucleotide sequences homologous to the genes sequenced from the studied eukaryotic species. Multiple nucleotide sequence alignments were achieved by using CLUSTALW [39]. The phylogenetic tree was constructed using the NeighbourJoining method boot strapping [40]. The statistical significance of the resulting dendrograms was calculated by bootstrapping on 1000 replicates and the values of bootstrap were shown as percentages.

\section{Growth measurement}

The microalgae growth was determined by estimating cell concentration from the absorbance at a $680 \mathrm{~nm}$ (i.e., $\mathrm{A}_{680}$ ) measured with a spectrometer (T60-UV-Visible Spectrometer, UK). After cultivation, cell pellets were obtained by centrifugation at $4500 \times g$ for $10 \mathrm{~min}$ at late exponential phase. Pellets were then dried at $105{ }^{\circ} \mathrm{C}$ until their weight kept constant. The dried microalgae were weighed to determine their dry biomass weight (DW). Data of growth in Box-Behnken experiments were presented as mean with standard deviation $( \pm \mathrm{SD})$.

\section{Total lipid extraction}

Total lipid extraction was carried out from dry biomass according to the method of Folch et al. [41] as modified by Bligh and Dyer [42]. The dry cells from $50 \mathrm{~cm}^{3}$ cultures were extracted using $3 \mathrm{~cm}^{3}$ chloroform/methanol/water $(2 / 1 / 1)$. Then, the mixture was agitated for $15 \mathrm{~min}$ in orbital shaker at $100 \mathrm{rpm}$ at room temperature. The extract was centrifuged $(10 \mathrm{~min}$ at $8000 \times g)$ and the organic phase was recovered. The pellet was re-extracted in $3 \mathrm{~cm}^{3}$ chloroform/methanol/water solution three times. Finally, the solvent phases were combined and evaporated to yield the lipid content that was calculated using the following equation: Lipid content $(\%)=\mathrm{W}_{\mathrm{L}} / \mathrm{W}_{\mathrm{A}} \times 100 \%$

Where $\mathrm{W}_{\mathrm{L}}(\mathrm{g})$ is the extracted lipids weight and $\mathrm{W}_{\mathrm{A}}(\mathrm{g})$ is the dry algae biomass.

Gravimetric analysis of lipid content of Box-Behnken experiments were performed in duplicate, and data were presented as means with standard deviation $( \pm S D)$.

\section{Experimental design and analysis of the response surface}

The level of the significant factors and the interaction effects between culture conditions which influence cells abundance and lipid production were analyzed and optimized by Box-Behnken methodology [43]. In this study, the experimental design contained 15 trials for optimizing culture conditions and the independent variables were studied at three levels, which are low $(-1)$, medium (0) and high (+1) (Table 1) [44].

The growth $\left(\mathrm{Y}_{1}\right)$ and lipid content $\left(\mathrm{Y}_{2}\right)$ were taken as the response values of the design. The different factor levels and response values are shown in Table 1 and Table 2, respectively. The optimal values were derived from the result analysis by using the NemrowdW Software (LPRAI, Marseille) [45]. The experimental data obtained from the Box-Behnken model experiments can be represented by the following quadratic polynomial Eq. (1):

$$
\mathrm{Y}=\beta_{0}+\sum \beta_{\mathrm{i}} X_{i}+\sum \beta_{\mathrm{ii}} X_{i}^{2}+\sum \beta_{\mathrm{ij}} X_{i} X_{j}
$$

Where $Y$ is the response variable; $\beta_{0}$ is a constant; $X_{i}$ and $X_{j}$ are the coded variable ranging between +1 and $-1 ; \beta_{\mathrm{i}}, \beta_{\mathrm{ii}}$ and $\beta_{\mathrm{ij}}$ are the linear, quadratic, and interaction effect coefficients, respectively. The plan of Box-Behnken in coded levels of the independent variables is shown in Tables 1 and 2.

\section{Nile red staining of cells}

Nile red (NR) (9-(diethyl amino) benzo[a]phenoxazin$5(5 \mathrm{H})$-one, Sigma-Aldrich) was dissolved in acetone as a stock solution of $250 \mathrm{mg} \cdot \mathrm{dm}^{-3}$. After cultivation, microalgae cells were stained with NR $\left(2 \mu \mathrm{g} . \mathrm{cm}^{-3}\right)$ at room temperature, shaken for $1 \mathrm{~min}$ on a vortex mixer and incubated for $15 \mathrm{~min}$ in darkness. After the incubation period, samples were directly analyzed by flow cytometry (FCM) and optical microscopy.

\section{Flow cytometry}

Counting and characterization of the selected strain were analyzed by FCM using a LSR flow cytometer (Becton Dickinson Biosciences) equipped with a $488 \mathrm{~nm}$ argon laser. The sample cells were entrained in the core of a sheath fluid so that they were individually intercepted by the laser beam, generating scatter and fluorescence signals. The forward scatter signal is related to the cell size and the sideward scatter signal to the cell structure and granularity. In addition to the scatter signals, two fluorescence signals were recorded, namely that of NR orange fluorescence ( $\lambda$ Excitation/ $\lambda$ Emission; 526/575 nm) after cell-lipid staining, and red fluorescence of chlorophyll $a$ ( $\lambda$ Excitation/Emission 613/682 nm). The LSR flow cytometer was under the control of the Cell Quest Pro

Table 1 Variables and experimental levels for optimising culture conditions

\begin{tabular}{lllll}
\hline Factors & Coded symbol & \multicolumn{3}{l}{ Levels } \\
\hline Levels & & -1 & 0 & +1 \\
Salinity & $X_{1}$ & 20 & 30 & 40 \\
Light intensity $\left(\mu \mathrm{mol}\right.$ photons. $\left.\mathrm{m}^{-2} \cdot \mathrm{s}^{-1}\right)$ & $\mathrm{X}_{2}$ & 84 & 133 & 182 \\
$\mathrm{pH}$ & $\mathrm{X}_{3}$ & 6 & 7 & 8 \\
\hline
\end{tabular}


Table 2 Results from Box-Behnken experiments: optimizing culture conditions for $V_{2}$ strain growth and lipid production

\begin{tabular}{|c|c|c|c|c|c|}
\hline Exp no. & Salinity $\left(X_{1}\right)$ & $\begin{array}{l}\text { Light intensity }\left(X_{3}\right) \\
\left(\mu \mathrm{mol} \text { photons. } \mathrm{m}^{-2} \cdot \mathrm{s}^{-1}\right)\end{array}$ & $\mathrm{pH}\left(\mathrm{X}_{3}\right)$ & Growth $\left(A_{680 \mathrm{~nm}}\right)\left(Y_{1}\right)$ & Lipids (a.u.) $\left(Y_{2}\right)$ \\
\hline 1 & 30 & 84 & 6 & $0.54 \pm 0.013$ & $1836.05 \pm 0.08$ \\
\hline 2 & 40 & 133 & 6 & $0.56 \pm 0.0205$ & $2031.44 \pm 0.285$ \\
\hline 3 & 30 & 182 & 6 & $0.57 \pm 0.0305$ & $2198.52 \pm 0.075$ \\
\hline 4 & 20 & 133 & 6 & $0.57 \pm 0.012$ & $1103.61 \pm 0.012$ \\
\hline 5 & 20 & 84 & 7 & $0.44 \pm 0.016$ & $978.00 \pm 0.26$ \\
\hline 6 & 40 & 84 & 7 & $0.51 \pm 0.033$ & $1491.41 \pm 0.21$ \\
\hline 7 & 40 & 182 & 7 & $0.52 \pm 0.022$ & $2675.11 \pm 0.2$ \\
\hline 8 & 20 & 182 & 7 & $0.60 \pm 0.001$ & $980.76 \pm 0.06$ \\
\hline 9 & 30 & 84 & 8 & $0.45 \pm 0.0015$ & $1860.83 \pm 0.32$ \\
\hline 10 & 20 & 133 & 8 & $0.57 \pm 0.02$ & $1400.50 \pm 0.025$ \\
\hline 11 & 30 & 182 & 8 & $0.59 \pm 0.019$ & $2604.73 \pm 0.035$ \\
\hline 12 & 40 & 133 & 8 & $0.47 \pm 0.0025$ & $2021.83 \pm 0.12$ \\
\hline 13 & 30 & 133 & 7 & $0.71 \pm 0.003$ & $2401.15 \pm 0.14$ \\
\hline 14 & 30 & 133 & 7 & $0.70 \pm 0.012$ & $2250.30 \pm 0.035$ \\
\hline 15 & 30 & 133 & 7 & $0.68 \pm 0.009$ & $2337.83 \pm 0.055$ \\
\hline
\end{tabular}

Lipid content was given as area detected into standard experimental conditions

software (Becton Dickinson, UK) that was also used for data recording. It is necessary to note that all the mentioned FCM analyses were run the same day with the same setting of the instrument. The data analysis was conducted with the SUMMIT ${ }^{\text {тм }}$ (DAKO) software. Cell clusters were distinguished on the basis of their optical properties.

\section{Microscopical determination of lipid content in microalgae cells stained by NR}

An epifluorescence microscope, Axio Observer Z1 (Carl Zeiss, Oberkochen, Germany), was used to observe at $600 \mathrm{~nm}$ the fluorescence of NR-stained microalgae upon excitation at $555 \mathrm{~nm}$, and to take pictures of the stained cells.

\section{Extraction of total lipids and Gas Chromatography} Coupled with Flame Ionization Detector (GC-FID) Analysis Fatty acid methyl esters (FAME) were produced from microalgal oil according to Laguerre et al. [46]. The analysis of FAME was conducted using gas chromatography (model 6890, Agilent Technologies, SGE, Courtaboeuf, France) equipped with a Supelcowax 10 capillary column (length, $30 \mathrm{~m}$; i.d., $0.32 \mathrm{~mm}$; film thickness, $0.25 \mathrm{~mm}$ ). Helium was used as a carrier gas with a flow rate of $1 \mathrm{~cm}^{3}$. $\min ^{-1}$. The injector and the Flame Ionization Detection (FID) were kept as $250{ }^{\circ} \mathrm{C}$ and $270{ }^{\circ} \mathrm{C}$, respectively. The initial column temperature was set at $150{ }^{\circ} \mathrm{C}$ and raised to $225^{\circ} \mathrm{C}$ at $5^{\circ} \mathrm{C} \cdot \mathrm{min}^{-1}$. FAMEs were characterized by Gas
Chromatographic (GC) comparison with commercially available FAMEs as internal standards.

\section{Separation of total lipid content by Thin Layer Chromatography}

The separation of polar and neutral lipids was performed by mono-dimensional High Performance-Thin Layer Chromatography (HP-TLC) using Silicagel 60 F254 plates $(20 \times 10 \mathrm{~cm})($ Merck, Germany) as a stationary phase [46] The HP-TLC analysis was carried out for microalgal-oil samples. The mobile phase was composed of chloroforme/methanol/acetic acid $(70 / 30 / 1 ; \mathrm{v} / \mathrm{v} / \mathrm{v})$ and hexane/ ether/acetic acid $(95 / 5 / 1 ; \mathrm{v} / \mathrm{v} / \mathrm{v})$ for polar lipids (diacylglycerol, monacylglycerol, free fatty acids (FFA), sterols, monogalactosyldiacylglycerol (MGDG), digalactosyldiacylglycerol (DGDG)) and neutral lipids (triacylglycerols (TAG)), respectively. Detection of lipids was performed by spraying the plates with $\mathrm{CuSO}_{4}$ solution. Then, the plates were placed in the steriliser for $10 \mathrm{~min}$ at $120^{\circ} \mathrm{C}$ [46].

\section{Results and discussion}

Isolation and molecular identification of the microalgae In the current study, after screening 20 strains isolated from the Mediterranean coast in the region of Sidi Mansour (Sfax, Tunisia), a microalgal species labelled $V_{2}$ was selected for further analysis on the basis of its morphological characteristics, purity, growth rate and oil content in a preliminary study. 
To specify the taxonomic position of this microalgal species, the partial $23 \mathrm{~S}$ region of the DNA gene amplified by PCR was sequenced. Phylogenetic analysis based on $23 \mathrm{~S}$ rDNA showed that the $\mathrm{V}_{2}$ strain was related to a species of the Tetraselmis genus (data not shown) with homology percentage of $99 \%$. The phylogenetic position is very near to Tetraselmis striata.

\section{Culture conditions optimization of cell abundance and lipid production by $\mathrm{V}_{2}$ strain}

Table 2 shows the results of different combinations of three factors (salinity, light intensity and $\mathrm{pH}$ ) chosen for optimizing $V_{2}$ strain cell abundance and lipid production.

Optimal culture conditions and statistical analysis of Box-Behnken Design results were further explored using NemrowdW Software (Table 2).

After identification of factors affecting cell growth and lipid production, the experimental data were fitted by the following Eqs. (2) and (3), second order polynomials established by multiple regression analysis:

$$
\begin{aligned}
\mathrm{Y}_{1}= & 0.697+0.042 X_{2}-0.02 X_{3}-0.087 X_{1}{ }^{2}-0.092 X_{2}{ }^{2} \\
& -0.067 X_{3}^{2}-0.037 X_{1} X_{2}+0.028 X_{2} X_{3} \\
\mathrm{Y}_{2}= & 2329.760+469.564 X_{1} \\
& +286.552 X_{2}-642.012 X_{1}{ }^{2} \\
& +295.337 X_{1} X_{2}
\end{aligned}
$$

Where $Y_{1}$ is the predicted cell abundance; $Y_{2}$ is the predicted lipid content; $\mathrm{X}_{1}$ is salinity; $\mathrm{X}_{2}$ is light intensity and $\mathrm{X}_{3}$ is $\mathrm{pH}$.

\section{Analysis of variance (ANOVA) and statistical analysis}

ANOVA was used to test the fit significance of quadratic polynomial equation for experimental data. The correlation value was used as a tool to test the quality of the model whereas the p-values were used to check the significance of each coefficient and the interactions between variables. The $\mathrm{R}^{2}$ values of 0.982 and 0.985 linked to cell abundance and lipid production according to Eqs. (2) and (3) respectively, indicated a good agreement between the experimental against predicted values for all responses (Tables 3 and 4).
Furthermore, the analysis of validity values indicated that the lack of fit of model terms was not significant $(P>0.05)$ which was considered a cue for the good quality of both models (Tables 3 and 4).

The ANOVA analysis revealed that the quadratic effect of both, salinity $\left(\mathrm{X}_{1}^{2}\right)$ and light intensity $\left(\mathrm{X}_{2}^{2}\right)$, on cell abundance was significant $(P<0.05)$ (Table 5), which was confirmed by the two (2D) and three (3D) dimensional response surface plots displayed in Fig. 1.

A cross referencing to ANOVA analysis confirmed that the salinity $\left(\mathrm{X}_{1}\right)$, light intensity $\left(\mathrm{X}_{2}\right)$, quadratic salinity effect $\left(\mathrm{X}_{1}^{2}\right)$ and interaction between both factors $\left(\mathrm{X}_{1} \mathrm{X}_{2}\right)$ were actually very significant $(P<0.05)$ in promoting lipid production by $\mathrm{V}_{2}$ strain cells grown in $\mathrm{F} / 2$ medium (Table 6).

\section{Culture condition effects on $\mathbf{V}_{\mathbf{2}}$ strain growth}

According to Khatoon et al. [47], it was demonstrated that salinity, light intensity and $\mathrm{pH}$ were the important factors that influence the green-microalgae growth. Considering the contour plots and the corresponding 3D response surface plot (Fig. 1), the thighest cell abundance $\left(\mathrm{A}_{680 \mathrm{~nm}}=0.7 \pm 0.01\right)$ was observed at intermediate values for $\mathrm{pH}(7)$, salinity (30) and light intensity $(133 \mu \mathrm{mol}$ photons. $\mathrm{m}^{-2} \cdot \mathrm{s}^{-1}$ ) (Fig. 1a and b). Therefore, the growth of this strain was reduced at low and at high salinity because of accumulation of osmo-protectant solutes shielding enzyme metabolism [48]. Similarly, Bartley et al. [49] reported that high salinity resulted in cellabundance decrease, which was also confirmed by the study of Khatoon et al. [47] when Nannochloropsis sp. and Tetraselmis sp. were cultured at salinity: 40. These results were further supported by Allakhverdiev et al. [50] who reported that the high salinity inhibited protein synthesis by inactivating ATP-synthase.

For light intensity stress, Cheirsilp and Torpee [51] showed that the maximum level of Nannochloropsis sp. growth was obtained by increasing light intensity up to 10 000 Lux $\left(135 \mu \mathrm{mol}\right.$ photons. $\left.\mathrm{m}^{-2} \cdot \mathrm{s}^{-1}\right)$ which was in accordance with findings of this study $\left(133 \mu \mathrm{mol}\right.$ photons. $\left.\mathrm{m}^{-2} . \mathrm{s}^{-1}\right)$. Chen et al. [52] stated also that the high light intensity inhibited the growth of microalgae which was consistent with the absorbance decrease observed when Tetraselmis sp. was cultivated under high light intensity. Khatoon et al. [47] reported that the highest absorbance of Nannochloropsis sp.

Table 3 Variance analysis for cells abundance response

\begin{tabular}{lclllll}
\hline Source of variation & Sum of squares & Degrees of freedom & Mean square & Ratio & Significance (\%) & Significance \\
\hline Regression & 0.0962 & 9 & 0.0107 & 30.2537 & $0.0777^{\mathrm{a}}$ & Significant \\
Residual & 0.0018 & 5 & 0.0004 & & & Not significant \\
Lack of fit & 0.0013 & 3 & 0.0004 & 1.8571 & 36.9 & \\
Error & 0.0005 & 2 & 0.0002 & & \\
Total & 0.0980 & 14 & & & \\
\hline
\end{tabular}

$\mathrm{R}^{2}=0.982$, ${ }^{\mathrm{a}}$ Significant at $99.9 \%$ 
Table 4 Variance analysis for lipid production response

\begin{tabular}{|c|c|c|c|c|c|c|}
\hline Source of variation & Sum of squares & Degrees of freedom & Mean square & Ratio & Significance (\%) & Significance \\
\hline Regression & $\begin{array}{l}4.45871 \\
E+0006\end{array}$ & 9 & $4.95413 E+0005$ & 35.8982 & $0.0514^{a}$ & Significant \\
\hline Residual & $\begin{array}{l}6.90025 \\
E+0004\end{array}$ & 5 & $\begin{array}{l}1.38001 \\
E+0004\end{array}$ & & & \\
\hline Lack of fit & $\begin{array}{l}5.75269 \\
E+0004\end{array}$ & 3 & $\begin{array}{l}1.92034 \\
E+0004\end{array}$ & 3.3420 & 23.9 & Not significant \\
\hline Error & $\begin{array}{l}1.14755 \\
E+0004\end{array}$ & 2 & $\begin{array}{l}5.73777 \\
E+0003\end{array}$ & & & \\
\hline Total & $\begin{array}{l}4.52772 \\
E+0006\end{array}$ & 14 & & & & \\
\hline
\end{tabular}

$\mathrm{R}^{2}=0.985$, ${ }^{\text {a Significant }}$ at $99.9 \%$

cultures was reached at $\mathrm{pH}$ 8.5. The above reported experiments are also supported by findings of Khalil et al. [53] who reported that the Dunaliella bardawil dry-mass production was maximal at $\mathrm{pH} 7.5$ and lower at $\mathrm{pH} 10$ and $\mathrm{pH} 4$.

\section{Culture condition effects on lipid content in $\mathbf{V}_{\mathbf{2}}$ strain}

Any fluctuation of several factors lead to the production of intracellular lipids. It was reported by Mata et al. [29] and Khatoon et al. [47] that Tetraselmis sp. and Nannochloropsis sp. were the best known microalgae that produce high lipid content (20-50\% DW).

To investigate the interaction between culture conditions (salinity, light intensity and $\mathrm{pH}$ ) on $\mathrm{V}_{2}$ strain lipid production, the two and three dimensional response surfaces were considered (Fig. 2).

When maintaining the light intensity at $133 \mu \mathrm{mol}$ photons. $\mathrm{m}^{-2} \cdot \mathrm{s}^{-1}$, the lipid production increased gradually with $\mathrm{pH}$ increasing from 6 to 7.6 and salinity ranging from 20 to 33.6 (Fig. 2b). This result disagreed with observations by Dahmen et al. [40] who showed that an increase in salinity inhibited cell growth as well as lipid synthesis of Picochlorum sp. Considering the cell abundance results, the best lipid production was achieved

Table 5 Coefficient statistical-analysis for cell abundance response

\begin{tabular}{lccl}
\hline Coefficients & Coefficient values & Student test & Significance (\%) \\
\hline b0 & 0.697 & 64.19 & $<0.01^{\mathrm{a}}$ \\
b1 & -0.015 & -2.26 & 7.4 \\
b2 & 0.042 & 6.40 & $0.139^{\mathrm{b}}$ \\
b3 & -0.020 & -3.01 & $2.98^{\mathrm{c}}$ \\
b11 & -0.087 & -8.90 & $0.029^{\mathrm{a}}$ \\
b22 & -0.092 & -9.41 & $0.022^{\mathrm{a}}$ \\
b33 & -0.067 & -6.86 & $0.101^{\mathrm{b}}$ \\
b12 & -0.037 & -3.99 & $1.04^{\mathrm{c}}$ \\
b13 & -0.023 & -2.39 & 6.2 \\
b23 & 0.028 & 2.93 & $3.28^{\mathrm{c}}$ \\
\hline
\end{tabular}

${ }^{\mathrm{a}}$ Significant at $99.9 \%,{ }^{\mathrm{b}}$ Significant at $99 \%,{ }^{\mathrm{C}}$ Significant at $95 \%$ when light intensity was at its maximum level $(188 \mu \mathrm{mol}$ photons. $\left.\mathrm{m}^{-2} \cdot \mathrm{s}^{-1}\right)$, the salinity at 37.23 and $\mathrm{pH}$ at 7 (Fig. 2a). On the other hand, the effect of $\mathrm{pH}\left(\mathrm{X}_{3}\right)$ on lipid production was not significant (Table 6).

Similar investigations have been performed by other researchers using alternative microalgae species. The investigations conducted with Scenedesmus abundans showed that the highest lipid content was $32.77 \%$ DW under a light intensity of $6000 \mathrm{Lux}$ (resembling a PAR of $81 \mu \mathrm{mol}$ photons. $\mathrm{m}^{-2} \cdot \mathrm{s}^{-1}$ when using our lamps), whereas, the lowest lipid content $(21.20 \% \mathrm{DW})$ corresponded to a light intensity of 3000 Lux $\left(40.5 \mu \mathrm{mol}\right.$ photons. $\left.\mathrm{m}^{-2} \cdot \mathrm{s}^{-1}\right)$ [20]. Independtly, Nannochloropsis oleoabundans HK-129 produced its highest lipid content under a light intensity of 14 800 Lux $\left(199.8 \mu\right.$ mol photons. $\left.\mathrm{m}^{-2} \cdot \mathrm{s}^{-1}\right)$ [15]. According to He et al. [10], the maximum lipid content of Chlorella sp. L1 (33.03\% DW) was reached under a light intensity of $400 \mu \mathrm{mol}$ photons. $\mathrm{m}^{-2} \cdot \mathrm{s}^{-1}$.

Any salinity variation would induce biochemical and physico-chemical changes in microalgae. This statement was supported by Kalita et al. [54] who reported that salinity stress resulted in an increased lipid production that was related to changes in fatty acid metabolism. According to $\mathrm{Hu}$ [55], a salinity increase from 10 to 35 would lead to a lipid content increase in microalgae. With the highest lipid content observed at a salinity of 37.23 , the present study is in agreement with these findings. Talebi et al. [56] demonstrated that the osmotic pressure on microalgae cells activated several responses such as regulation of ion transport through the plasma membrane, and synthesis of stress proteins to maintain a constant growth and to accumulate osmo-protectant solutes. These processes were paralleled by an increased lipid accumulation. Similarly to the results reported by Khatoon et al. [47], the maximum lipid content produced in the present study was reached at $\mathrm{pH} 7$. According to Bondioli et al. [57], the lipid content produced by Tetraselmis suecica FEM-M33 amounted to 22, 27 and 29\% DW under nitrogen starvation, nitrogen and phosphorus starvation, and nutrient repletion, respectively. 

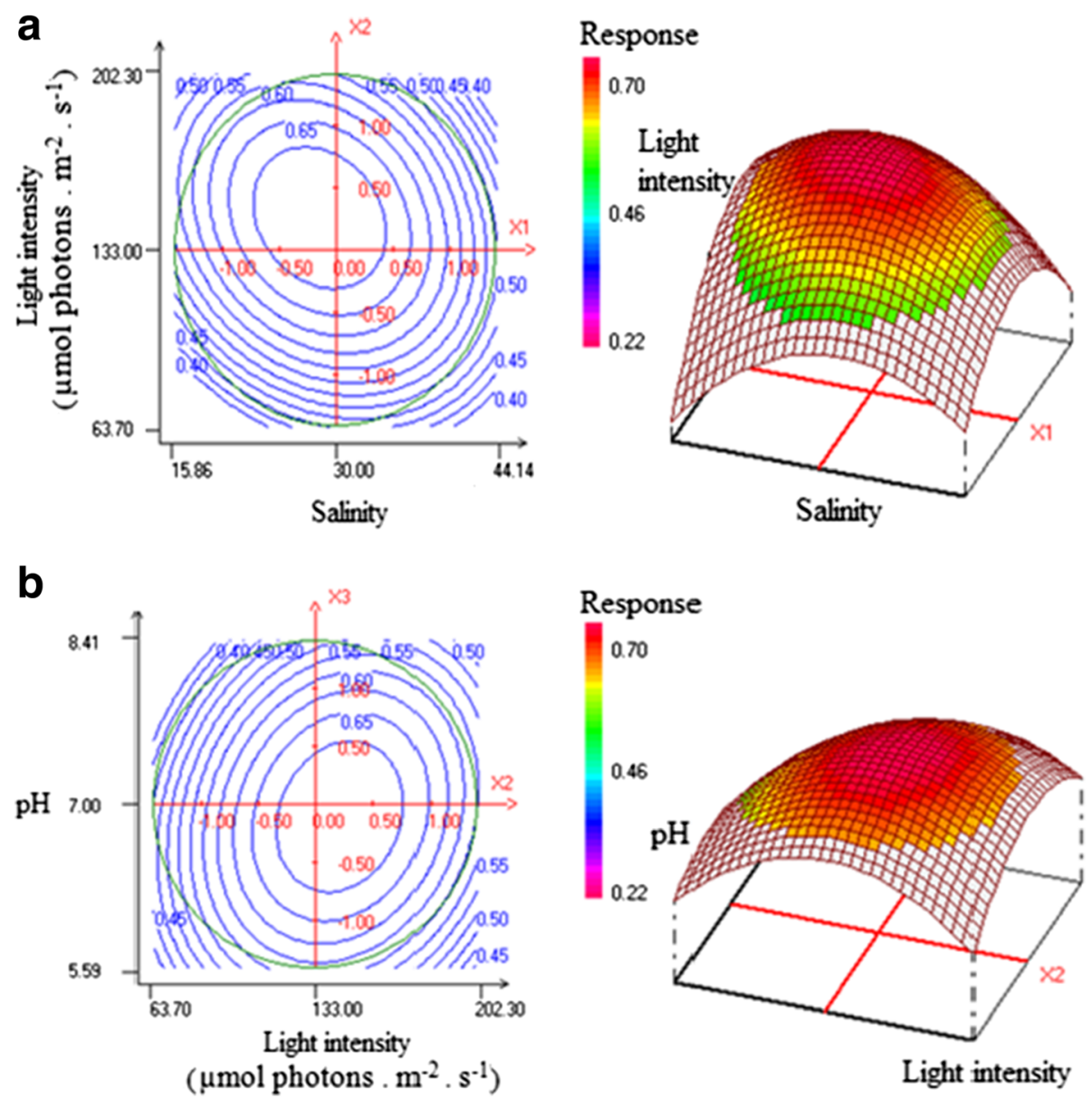

Fig. 1 Contour plots and the corresponding cells abundance response surface plot. a Effects of salinity and light intensity on cell abundance. b Effects of $\mathrm{pH}$ and light intensity on cell abundance

Table 6 Coefficient statistical analysis for lipid production response

\begin{tabular}{lccc}
\hline Coefficients & Coefficient values & Student test & Significance (\%) \\
\hline b0 & 2329.760 & 34.35 & $<0.01^{\mathrm{a}}$ \\
b1 & 469.564 & 11.31 & $<0.01^{\mathrm{a}}$ \\
b2 & 286.552 & 6.90 & $0.0980^{\mathrm{a}}$ \\
b3 & 89.784 & 2.16 & 8.3 \\
b11 & -642.012 & -10.50 & $0.0136^{\mathrm{a}}$ \\
b22 & -156.325 & -2.56 & 5.1 \\
b33 & -48.402 & -0.79 & 46.4 \\
b12 & 295.337 & 5.03 & $0.401^{\mathrm{b}}$ \\
b13 & -76.625 & -1.30 & 24.9 \\
b23 & 95.357 & 1.62 & 16.5 \\
\hline
\end{tabular}

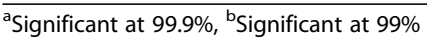

The main novelty of the present work was to investigate the combination and interaction effect of three important environmental factors $(\mathrm{pH}$, salinity and light intensity). This way, growth conditions could be identified, which lead to the highest lipid production level (49\% DW) by $\mathrm{V}_{2}$ strain. This is a lipid content higher than that reported by Khatoon et al. [47] as well as other studies. The highest Tetraselmis sp. lipid content determined by gravimetric method corresponded to culture condition $7(45.4 \pm 0.2 \% \mathrm{DW})$, followed by culture condition 11 (39.31 $\pm 0.013 \%$ DW) (Fig. 3). These values were higher than that reported by $\mathrm{Hu}$ et al. [58] for oleaginous green algae. Tetraselmis sp. was also singled out as a high lipid producer in previous studies $[22,59]$.

\section{Validation of the model}

The culture conditions optimized for cell abundance were as follows: salinity: 30; light intensity: $133 \mu \mathrm{mol}$ photons. $\mathrm{m}^{-2} \cdot \mathrm{s}^{-1} ; \mathrm{pH}: 7$. The optimized culture conditions for lipid production were salinity: 37.23; light intensity: $188 \mu \mathrm{mol}$ photons. $\mathrm{m}^{-2} \cdot \mathrm{s}^{-1}$; $\mathrm{pH}: 7$. 

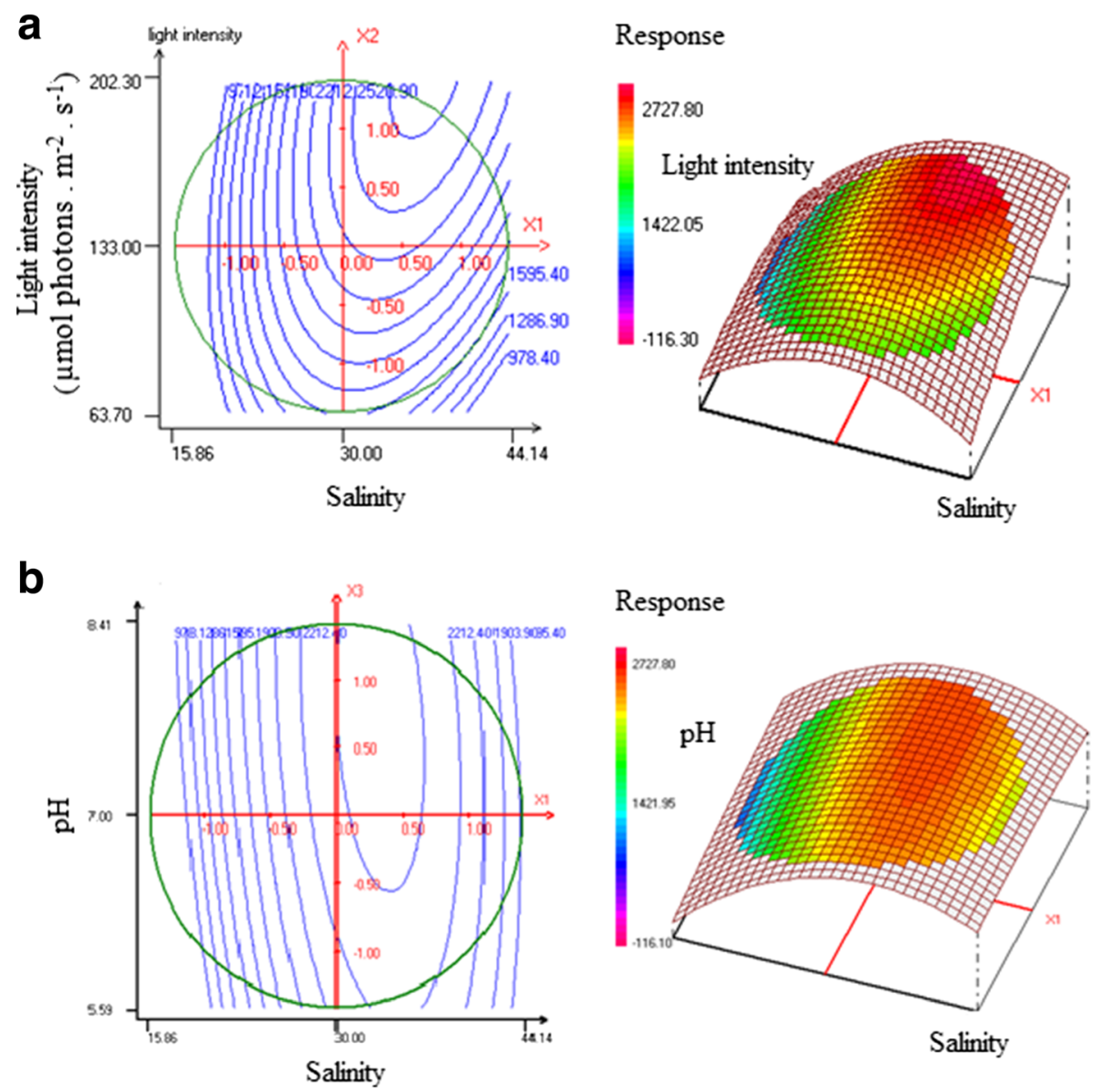

Fig. 2 Contour plots and the corresponding lipid response surface plot. a Effects of salinity and light intensity on lipid production. $\mathbf{b}$ Effects of pH and light intensity on lipid production

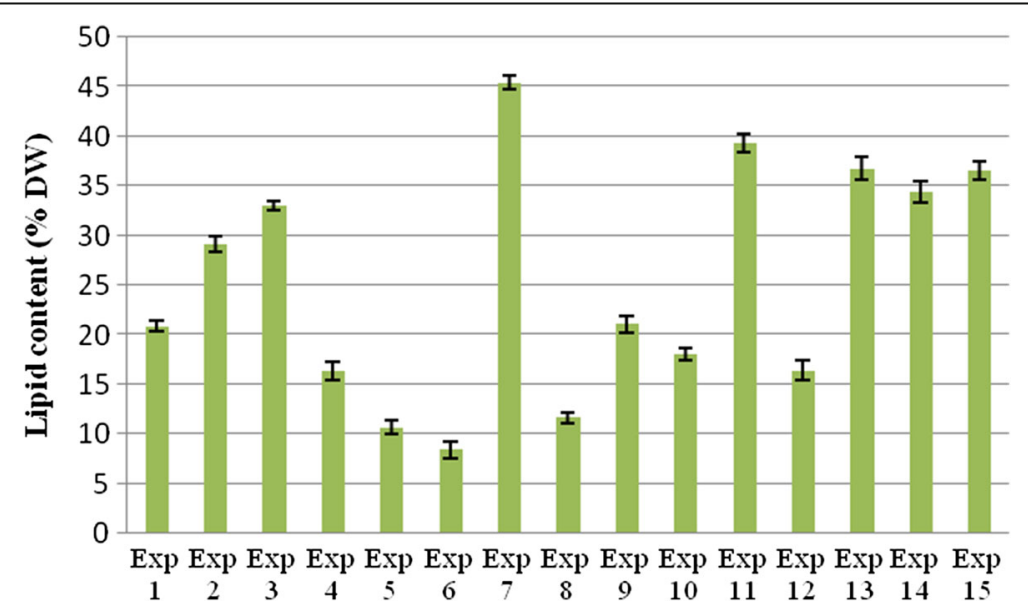

Fig. 3 Tetraselmis sp. lipid content (\% DW) determined by the gravimetric method under different culture conditions 
After 15 days of $\mathrm{V}_{2}$ strain growth under optimized culture conditions, cell absorbance and lipid production reached $0.7 \pm 0.01$ and $49 \pm 2.1 \%$ DW, respectively. The lipid production was 2.6 times higher than that obtainable with cultures in $\mathrm{F} / 2$ medium under standard conditions: salinity: 41; light intensity: $84 \mu \mathrm{mol}$ photons. $\mathrm{m}^{-2} \cdot \mathrm{s}^{-1}$ and pH: 7.6, which emphasizes the Tetraselmis sp. high efficiency in lipid production. These results demonstrate the great usefulness of the Bok-Behnken methodology to optimize growth factors and study their interaction in order to achieve the highest oil production.

\section{Flow cytometry and epifluorescence microscopy observations}

In stressed culture, neutral lipids (NL) are the major component of microalgal oils. These NL represent total lipids stored in cells. They consist in energy reserve bodies of TAG [60]. The microalgae lipid content was quantified by FCM after staining the intracellular lipid bodies with the lipophilic dye NR [61, 62], as reported by Teo et al. [63]. Silva et al. [64] established a linear correlation between the total NR fluorescence recorded by FCM and the total microalgal lipid content determined by the gravimetric method $[65,66]$, making NR staining a promising method for cell lipid quantification. Figure 4 displays typical FCM cytograms of $V_{2}$ strain grown under conditions 4,5 and 7 .
The dot plots representing red fluorescence versus orange fluorescence or orange fluorescence versus the forward scatter signal reveal the existence of two subgroups differentiated by their fluorescence intensities. Two subgroups were observed under condition 4 (Fig. 4a). Each cluster is characterized by the median values of its variables that are reported in Table 7. In particular, $\mathrm{V}_{2}$ strain under condition 4 shows the largest median of red fluorescence, as well as the largest median of the size value. This is suggesting a "healthier" (larger chlorophyll content, larger size) cell production under condition 4 than under conditions 5 and 7.

Median values of Tetraselmis sp. flow cytometric variables were obtained in absence and presence of NR stained cells.

The cytograms corresponding to the NR stained samples (Fig. 4b) prove that not all Tetraselmis sp. cells respond to NR. Under condition 7, the subgroup with the highest median red fluorescence gave rise to the largest response to NR. Indeed, its median orange fluorescence was 2-fold more than that of the responding cells under condition 4 and 3-fold more than that of cells under condition 5, in agreement with results reported in Table 2 . Thus, the increase in cell lipid content appears to be linked to the light intensity increase from 84 to $182 \mu \mathrm{mol}$ photons. $\mathrm{m}^{-2} \cdot \mathrm{s}^{-1}$. This is consistent with the fact that low irradiance reduces $\mathrm{CO}_{2}$ assimilation as reported by Beardall et al. [67].

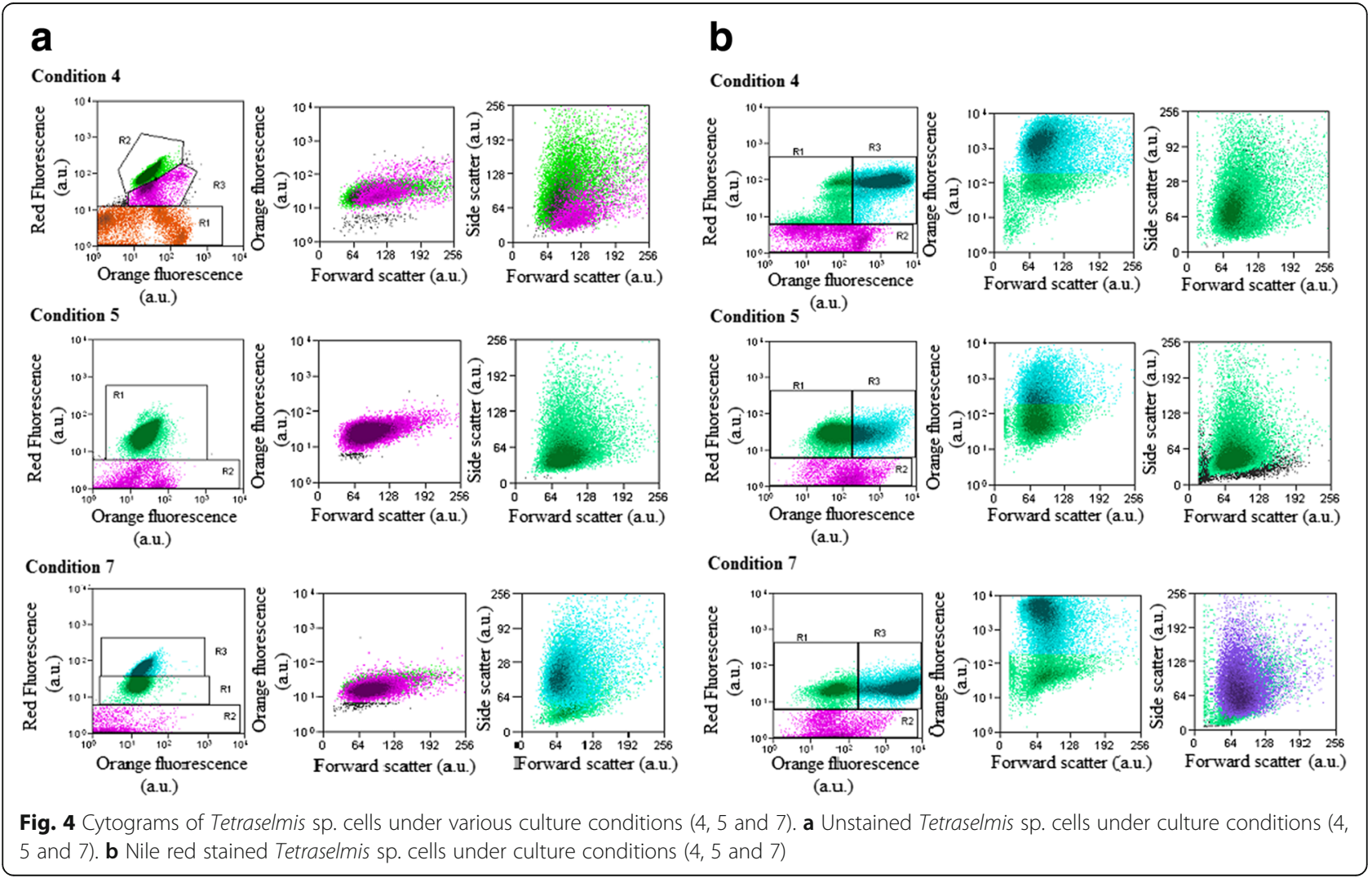


Table 7 Median values of Tetraselmis sp. flow cytometric variables

\begin{tabular}{lllll}
\hline $\begin{array}{llll}\text { Conditions } \\
\text { (4- 5-7) }\end{array}$ & $\begin{array}{l}\text { Red } \\
\text { fluorescence } \\
\text { (a.u.) }\end{array}$ & $\begin{array}{l}\text { Size } \\
\text { (a.u.) }\end{array}$ & $\begin{array}{l}\text { Structure } \\
\text { (a.u.) }\end{array}$ & $\begin{array}{l}\text { Orange } \\
\text { fluorescence } \\
\text { (a.u.) }\end{array}$ \\
\hline $\begin{array}{l}\text { Unstained cells } \\
\text { Condition 4 }\end{array}$ & 85 & 97 & 80 & 24.01 \\
Condition 4-R2 & 91.37 & & & 24.01 \\
Condition 4-R3 & 37.04 & & & 27.74 \\
Condition 5 & 27.74 & 89 & 53 & 24.89 \\
Condition 7 & 42.79 & 82 & 88 & 16.4 \\
Condition 7-R1 & 22.34 & & & 15.01 \\
Condition 7-R3 & 57.13 & & & 19.33 \\
Nile red stained cells & & & \\
Condition 4 & 73.56 & 90 & 79 & 481 \\
Condition 4-R1 & 34.46 & & & 81.98 \\
Condition 4-R3 & 85 & & & 1230.82 \\
Condition 5 & 24.89 & 82 & 54 & 557.69 \\
Condition 5-R1 & 26.76 & & & 44.75 \\
Condition 5-R3 & 27.74 & & & 811.97 \\
Condition 7 & 20.78 & 81 & 68 & 536.31 \\
Condition 7-R1 & 20.04 & & & 49.44 \\
Condition 7-R3 & 24.01 & & & 2724.55 \\
\hline
\end{tabular}

These experiments demonstrate that cell growth and lipid production are not tightly coupled and that the choice of the growth conditions depends on the selected priority, either biomass or lipids. The fact that a subpopulation of Tetraselmis sp. does not respond to NR staining deserves further investigation. Indeed, it would be important to find out if the observed cluster heterogeneity expresses real species heterogeneity. If so, the subspecies exhibiting the highest lipid content should be characterized to obtain the optimal lipid production.
This subspecies seems to correspond to the one with the highest chlorophyll content (Fig. 4b) which excludes the possibility to link its existence to an artifact of NR staining. Consequently, the FCM quantification open a way to further optimize lipid production by $\mathrm{V}_{2}$ strain.

The presence of lipid droplets inside Tetraselmis sp. cells revealed by NR staining was also observed by epifluorescence microscopy (Fig. 5). The photomicrographs showed the highest lipid accumulation inside cells cultured under condition 7 , followed by cells cultured under condition 4, whereas the lipid content was very low under condition 5 (Fig. 5). These observations are fully consistent with those made by FCM.

\section{Fatty acids composition}

Similar to plants, many species of microalgae can accumulate polar and neutral lipids as energy and carbon storage. In this study, results obtained with HP-TLC revealed that TAG, 1,2 diacylglycerol, 1,3 diacylglycerol and FFA were the principal components of Tetraselmis sp. extracted lipids. The Tetraselmis sp. fatty acid composition as determined by GC-FID analysis is displayed in Table 8.

Percentages values of fatty acids and total lipid content were measured when Tetraselmis sp. was cultured under optimized culture conditions for lipid production. The chemical formula of each fatty acid is indicated in parenthesis.

Harwood [68] reported that light intensity fluctuation can change the metabolism of lipids in green microalgae with modification of lipid class composition. Therefore, light intensity variations can modulate fatty acid synthesis.

In this study, $\mathrm{V}_{2}$ strain reached a total lipid content of $49 \pm 2.1 \%$, a value higher than the total lipid content found in Picochlorum sp. SBL2 (25.28 $\pm 2.38 \%)$, Nannochloris sp. SBL1 (19.69 $\pm 2.19 \%)$, Nannochloris sp. SBL4 $(22.65 \pm 2.21 \%)$ and Desmochloris sp. SBL3 $(23.16 \pm 3 \%)$
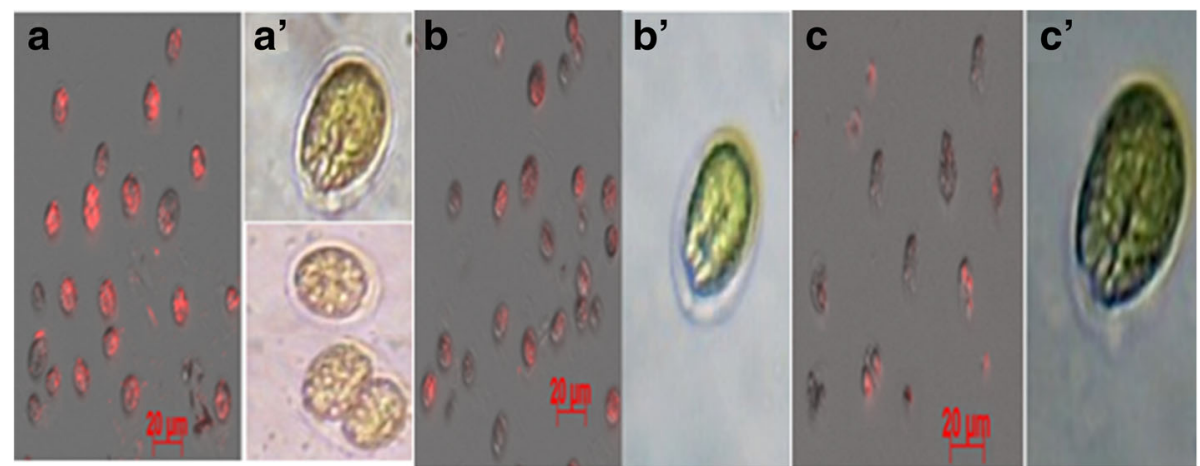

Fig. 5 Fluorescence microscopy images of Tetraselmis sp. grown under different conditions. (a, b and c) correspond to fluorescence images of cells stained with NR (Excitation wavelength centered at $555 \mathrm{~nm}$ and fluorescence emission wavelength centered at $600 \mathrm{~nm}$ ) to highlight the lipid droplets (red) cultured under indicated conditions. ( $a^{\prime}, b^{\prime}$ and c') correspond to phase contrast images of corresponding culture conditions. (a and a') culture condition 7. (b and b') culture condition 4. (c and c') culture condition 5. All images of epifluorescence microscopy were taken at $\times 20$ magnification, while contrast images were taken at $\times 40$ magnification. Scale bar represents $20 \mu \mathrm{m}$ 
Table 8 Fatty acids composition and total lipid content of Tetraselmis sp.

\begin{tabular}{ll}
\hline Name & \% of the total FAME \\
\hline Saturated fatty acids & 0.82 \\
Myristic (14:0) & 30.89 \\
Palmitic (16:0) & 2.99 \\
Heptadecanoic (17:0) & 1.07 \\
Stearic (18:0) & 7.25 \\
(19:0) & 1.62 \\
Arachidic (20:0) & 44.68 \\
Total saturates & \\
Monounsaturated fatty acids & 5.58 \\
Palmitoleic (16:1) & 32.88 \\
Oleic (18:1) & 0.73 \\
Gadoleic (20:1) & 39.20 \\
Total monounsaturates & \\
Polyunsaturated fatty acids & 8.12 \\
Linoleic (18:2) & 1.84 \\
Linolenic (18:3) & 1.85 \\
Dihomolinoléic (20:2) & 0.85 \\
DGL (20:3) & 3.43 \\
EPA (20:5) & 16.10 \\
Total polyunsaturates & $49 \pm 2.1$ \\
Total lipids (\% DW) &
\end{tabular}

by Pereira et al. [69]. Hu et al. [58] reported that oleaginous chlorophyte can accumulate lipids up to an average of 25\% DW. GC profile showed a dominance of saturated and mono-saturated fatty acids representing more than $80 \%$ of the total fatty acid methyl esters (FAMEs). Oleic (C18:1) and Palmitic (C16:0) acids were the predominant fatty acids in autotrophic microalgae cultures, accounting for $32.88 \%$ and $30.89 \%$ of the total FAMEs, respectively. The finding that the third most abundant fatty acid, linoleic acid (C18:2) accounted for $8.12 \%$ of total fatty acids is in good agreement with reported contents in Monoraphidium [26], Nannochloris. SBL1 and Nannochloris sp. [69]. $\mathrm{V}_{2}$ strain was found to contain an important proportion of PUFAs and MUFAs, which accounted for $16.1 \%$ and $39.2 \%$ of the total FAMEs, respectively. These values were similar to results obtained by Selvakumar and Umadevi [70] who reported that the highest level of PUFAs (17.7\%) in $T$. gracilis was observed at low concentration of nitrate $\left(0.05 \mathrm{~g} \cdot \mathrm{dm}^{-3}\right)$. Moreover, the fatty acid profile showed the presence of important levels of omega $3(\omega 3)$, omega 6 $(\omega 6)$ and omega $9(\omega 9)$ that reached 5.28, 8.12 and 32.8\% of the total FAMEs, respectively. The EPA percentage amounted for $21.3 \%$ of total PUFAs, while a lower percentage of this fatty acid (14\% of total PUFAs) was recorded at $0.05 \mathrm{~g} . \mathrm{dm}^{-3}$ of nitrate in T. gracilis [70].

\section{Conclusions}

The oleaginous microalga Tetraselmis sp. was isolated and identified on the basis of $23 \mathrm{~S}$ rRNA gene. Optimization of light intensity, salinity and $\mathrm{pH}$ were crucial factors for oil production by green microalgae. In this work, a high cell density $\left(A_{680 n m}, 0.7\right)$ was achieved by the $V_{2}$ strain, when cultured at the following conditions: salinity: 30 , photosynthetic active light intensity: $133 \mu \mathrm{mol}$ photons. $\mathrm{m}^{-2} \cdot \mathrm{s}^{-1}$, and $\mathrm{pH}: 7$. The highest lipid content (49\% DW) was reached under the following conditions: salinity: 37.23; photosynthetic active light intensity: $188 \mu \mathrm{mol}$ photons.m ${ }^{-2} \cdot \mathrm{s}^{-1}$, and $\mathrm{pH}$ : 7. In the experiments presented here, it was demonstrated that combining several culture conditions can significantly enhance lipid production by this strain. In Tetraselmis sp., the percentage of total PUFAs was $16.1 \%$ under optimized culture conditions for lipid production. Results show the possibility of increasing growth, total lipid and fatty acid contents (essentially PUFAs), in Tetraselmis sp. cultures. The isolated Tetraselmis sp. strain proved to be ideal for lipid and PUFAs production.

\section{Abbreviations \\ 2D: Two dimensions; 3D: Three dimensions; A: Absorbance; a.u.: Arbitrary unit; ANOVA: Analysis of variance; BBD: Box-Behnken design; DGDG: Digalactosyldiacylglycerol; DW: Dry weight; EXP: Experiment; FAME: Fatty acid methyl ester; FCM: Flow cytometry; FFA: Free fatty acids; FID: Flame ionization detection; GC: Gas chromatography; HP-TLC: High performance-thin layer chromatography; MGDG: Monogalactosyldiacylglycerol; MUFA: Mono-saturated fatty acids; NL: Neutral lipids; NR: Nile red; PUFAs: Poly- unsaturated fatty acids; R: Subgroup; RSM: Response surface methodology; TAG: Triacylglycerols; $\omega 3$ : Omega 3; w6: Omega 6; w9: Omega 9}

\section{Acknowledgements}

The authors thank the Tunisian Ministry of higher education and scientific research for providing the funding for this research.

\section{Funding}

This work received financial support from « Ministère de l'enseignement supérieur et de la recherche scientifique ». The funding organism had no role in study design, data collection and analysis, decision to publish, or preparation of the manuscript.

\section{Availability of data and materials}

The dataset supporting the conclusions of this article is included within the article.

\section{Authors' contributions}

$\mathrm{MD}, \mathrm{SMH}, \mathrm{MB}, \mathrm{RM}$ and FBA carried out the molecular genetic studies, participated in the sequence alignment and drafted the manuscript. DG carried out the cytometry analysis. IF, CP and BH participated in the design of the study. SA, MD and IF conceived of the study, and participated in its design and coordination and helped to draft the manuscript. All authors read and approved the final manuscript.

\section{Competing interests}

The authors declare that they have no competing interests.

Consent for publication

Not Applicable.

Ethics approval and consent to participate

Not Applicable. 


\section{Author details}

'Biotechnologie des Algues, Biological Engineering Department, National School of Engineers of Sfax, University of Sfax, Sfax, Tunisia. Institute of Horticultural Production Systems, Section Biosystems Engineering, Leibniz University Hannover, Herrenhauser Str. 2, 30419 Hannover, Germany. ${ }^{3}$ Center for Molecular Biophysics (CBM), CNRS UPR4301, Orléans, France. ${ }^{4}$ Institute of Botany, Leibniz Universitaet Hannover, Herrenhauser Str. 2, 30419 Hannover, Germany. ${ }^{5}$ nit Research of Toxicology-Microbiology Environmental and Health UR1 1ES70, Faculty of Sciences of Sfax, University of Sfax, Sfax, Tunisia. ${ }^{6}$ Aix Marseille Université, Université de Toulon, CNRS/INSU, IRD, Institut Méditerranéen d'Océanologie (MIO), 163 avenue de Luminy, Case 901, 13288 Marseille Cedex 09, France.

\section{Received: 22 September 2016 Accepted: 11 November 2016} Published online: 05 December 2016

\section{References}

1. Takeyama H, Kanamaru A, Yoshino Y, Kakuta H, Kawamura Y, Matsunaga T. Production of antioxidant vitamins, beta-carotene, vitamin $C$, and vitamin $E$, by two-step culture of Euglena gracilis Z. Biotechnol Bioeng. 1997;53:185-90.

2. Chtourou H, Dahmen I, Hassairi I, Abdelkafi S, Sayadi S, Dhouib A. Dunaliella sp. a Wild Algal Strain Isolated from the Sfax-Tunisia Solar Evaporating Salt-Ponds, a High Potential for Biofuel Production Purposes. J Biobaased Mater Bioenergy. 2014;8:1-8.

3. Kumar P, Ramakritinan CM, Kumaraguru AK. Solvent extraction and spectrophotometric determination of pigments of some algal species from the shore of puthumadam, Southeast Coast of India. International Journal of Oceans and Oceanography. 2010;4:29-34.

4. Pal D, Khozin-Goldberg I, Cohen Z, Boussiba S. The effect of light, salinity, and nitrogen availability on lipid production by Nannochloropsis sp. Appl Microbiol Biotechnol. 2011;90:1429-41.

5. Matsumoto M, Sugiyama H, Maeda $Y$, Sato R, Tanaka T, Matsunaga T. Marine diatom, Navicula sp. strain JPCC DA0580 and marine green alga, Chlorella sp. strain NKG400014 as potential sources for biodiesel production. Appl. Biochem. Biotechnol. 2010;161:483-90.

6. Yao C, Ai J, Cao X, Xue S, Zhang W. Enhancing starch production of a marine green microalga Tetraselmis subcordiformis through nutrient limitation. Bioresour Technol. 2012;118:438-44.

7. Shahidi F, Wanasundara UN. Omega-3 fatty acid concentrates nutritional aspects and production technologies. Trends Food Sci Technol. 1998;9:230-40.

8. Horrocks LA, Yeo YK. Health benefits of docosahexaenoic acid. Pharmacol Res. 1999:40:211-25.

9. Nettleton AJ, editor. Omega-3 Fatty Acids and Health. New York: Chapman and Hall; 1995. p. 359.

10. Adarme-Vega TC, Thomas-Hall SR, Lim DKY, Schenk PM. Effects of long chain fatty acid synthesis and associated gene expression in microalga Tetraselmis sp. Mar Drugs. 2014;12:3381-98.

11. He Q, Yang $H$, Wu L, Hu C. Effect of light intensity on physiological changes, carbon allocation and neutral lipid accumulation in oleaginous microalgae. Bioresour Technol. 2015;191:219-28.

12. Brown MR, Dunstan GA, Norwood SJ, Miller KA. Effects of harvest stage and light on the biochemical composition of the diatom Thalassiosira pseudonana. J Phycol. 1996;32:64-73.

13. Tzovenis I, De Pauw N, Sorgeloos P. Optimisation of T-ISO biomass production rich in essential fatty acids: Effect of different light regimes on growth and biomass production. Aquaculture. 2003;216:203-22

14. Yang $\mathrm{H}, \mathrm{He} \mathrm{Q}$, Rong J, Xia L, Hu C. Rapid neutral lipid accumulation of the alkali-resistant oleaginous Monoraphidium dybowskii LB50 by $\mathrm{NaCl}$ induction. Bioresour Technol. 2014;172:131-7.

15. $X u X Q$, Beardall J. Effect of salinity on fatty acid composition of a green microalgae from an Antarctic hypersaline lake. Phytochemistry. 1997:45:655-8.

16. Sun $X$, Cao Y, Xu H, Liu Y, Sun J, Qiao D, Cao Y. Effect of nitrogen starvation, light intensity and iron on triacylglyceride/carbohydrate production and fatty acid profile of Neochloris oleoabundans HK-129 by a two-stage process. Bioresour Technol. 2014;155:204-12.

17. Mujtaba G, Choi W, Lee CG, Leea K. Lipid production by Chlorella vulgaris after a shift from nutrient-rich to nitrogen starvation conditions. Bioresour Technol. 2012:123:279-83.

18. Nogueira DPK, Silva AF, Araújo OQF, Chaloub RM. Impact of temperature and light intensity on triacylglycerol accumulation in marine microalgae. Biomass Bioenerg. 2015;72:280-87.
19. Zhu CJ, Lee YK, Chao TM. Effect of temperature and growth phase on lipid and biochemical composition of Isochrysis galbana TK1. J App Phycol. 1997:9:451-7.

20. Mclachlan JL, Curtis JM, Boutilier K, Keusgen M, Seguel MR. Tetreutreptia pomquetensis (Euglenophyta), a psychrophilic species: Growth and fatty acid composition. J Phycol. 1999;35:280-6.

21. Mandotra SK, Pankaj K, Suseela MR, Nayaka S, Ramteke PW. Evaluation of fatty acid profile and biodiesel properties of microalga Scenedesmus abundans under the influence of phosphorus, $\mathrm{pH}$ and light intensities. Bioresour Technol. 2016;201:222-9.

22. Wang ST, Pan YY, Liu CC, Chuang LT, Chen CNN. Characterization of a green microalga UTEX 2219-4: Effects of photosynthesis and osmotic stress on oil-body formation. Bot Stud. 2011;52(3):305-312.

23. Rodolfi L, Chini ZG, Bassi N, Padovani G, Biondi N, Bonini G, et al. Microalgae for oil: strain selection, induction of lipid synthesis and outdoor mass cultivation in a low-cost photobioreactor. Biotechnol Bioeng. 2009;102:100-12.

24. Studt T. Algae promise biofuel solutions. Inform. 2010;21:319-24.

25. Ho SH, Ye X, Hasunuma T, Chang JS, Kondo A. Perspectives on engineering strategies for improving biofuel production from microalgae - a critical review. Biotechnol Adv. 2014:32(8):1448-59.

26. Bellou S, Baeshen MN, Elazzazy AM, Aggeli D, Sayegh F, Aggelis G. Microalgal lipids biochemistry and biotechnological perspectives. Biotechnol Adv. 2014;32(8):1476-93.

27. Yu X, Zhao P, He C, Li J, Tang X, Zhou J, et al. Isolation of a novel strain of Monoraphidium sp. and characterization of its potential application as biodiesel feedstock. Bioresour Technol. 2012;121:256-62.

28. Hemaiswarya S, Raja R, Kumar RR, Ganesan V, Anbazhagan C. Microalgae: a sustainable feed source for aquaculture. World J Microbiol Biotechnol. 2011;27:1737-46.

29. Azma M, Mohamed MS, Mohamad R, Rahim RA, Ariff AB. Improvement of medium composition for heterotrophic cultivation of green microalgae, Tetraselmis suecica, using response surface methodology. Biochem Eng J. 2011:53(2):187-95.

30. Mata TM, Martins AA, Caetano NS. Microalgae for biodiesel production and other applications: a review. Renew Sustain Energy Rev. 2010;14:217-32.

31. D'Souza FML, Kelly GJ. Effects of a diet of a nitrogen-limited alga (Tetraselmis suecica) on growth, survival and biochemical composition of tiger prawn (Penaeus semisulcatus) larvae. Aquaculture. 2000;181:311-29.

32. Fabregas J, Otero A, Dominguez A, Patino M. Growth rate of the microalga Tetraselmis suecica changes the biochemical composition of Artemia species. Marin Biotechnol. 2001;3:256-63.

33. Huang $X$, Wei L, Huang Z, Yan J. Effect of high ferric ion concentrations on total lipids and lipid characteristics of Tetraselmis subcordiformis, Nannochloropsis oculata and Pavlova viridis. J Appl Phycol. 2014;26:105-14

34. Kimura K, Yamaoka M, Kamisaka Y. Rapid estimation of lipids in oleaginous fungi and yeasts using Nile red fluorescence. J Microbiol Methods. 2004;56:331-8.

35. Tornabene TG. Lipid composition of the nitrogen starved green alga Neochloris oleoabundans. Enzyme Microbiol Technol. 1983;5:435-40.

36. Guillard RRL. Culture of phytoplankton for feeding marine invertebrates. In: Smith WL, Chanley MH, editors. Cultures of Marine Invertebrate Animals. New York: Plenum Press; 1975, p. 26-60.

37. Haase SM, Panas P, Rath T, Huchzermeyer B. Effects of carbamazepine on two microalgae species differing in stress resistance. Water Air Soil Pollut. 2015;226:328.

38. Sherwood AR, Presting GG. Universal primers amplify a 23S rDNA plastid marker in eukaryotic algae and cyanobacteria. J Phycol. 2007;43:605-8.

39. Tamura K, Peterson D, Peterson N, Stecher G, Nei M, Kumar S. MEGA5: molecular evolutionary genetics analysis using maximum likelihood, evolutionary distance, and maximum parsimony methods. Mol Biol Evol. 2011:28(10):2731-9.

40. Dahmen I, Chtourou H, Jebali A, Daassi D, Karray F, Hassairi I, et al. Optimisation of the critical medium components for better growth of Picochlorum sp. and the role of stressful environments for higher lipid production. J Sci Food Agric. 2014:94(8):1628-38.

41. Folch J, Lees M, Sloane Stanley GH. Tissues total lipids from animal isolation and purification of a simple method for the article. J Biol Chem. 1957;226:497-509.

42. Bligh EG, Dyer WJ. A rapid method for the total lipid extraction and purification. Can J Biochem Physiol. 1959;37:911-7.

43. Box GEP, Behnken EW. Some new three level designs for the study of quantitative variables. Technometrics. 1960;2:455-75. 
44. Myers RH, Montgomery DC. Response Surface Methodology. New-York: Wiley; 1995.

45. Mathieu JE, Heffner TS, Goodwin GF, Salas E, Cannon-Bowers JA. The influence of shared mental models on team process and performance. Appl Psychol. 2000;85:273-83.

46. Laguerre M, López-Giraldo LJ, Lecomte J, Baréa B, Cambon E, Tchobo PF, et al. Conjugated autoxidizable triene (CAT) assay: A novel spectrophotometric method for determination of antioxidant capacity using triacylglycerol as ultraviolet probe. Anal Biochem. 2008;380:282-90.

47. Khatoon H, Abdu Rahman N, Banerjee S, Harun N, Suleiman SS, Zakaria NH, Lananan F, Abdul Hamid SH, Endut A. Effects of different salinities and pH on the growth and proximate composition of Nannochloropsis sp. and Tetraselmis sp. isolated from South China Sea cultured under control and natural condition. Int Biodeterioration \& Biodegradation. 2014;95:11-8.

48. Fatma T, Khan MA, Choudhary M. Impact of environmental pollution on cyanobacterial proline content. J Appl Phycol. 2007;19:625-9.

49. Bartley ML, Boeing WJ, Corcoran AA, Holguin FO, Schaub T. Effects of salinity on growth and lipid accumulation of biofuel microalgae Nannochloropsis salina and invading organisms. Biomass Bioenergy. 2013;54:83-8.

50. Allakhverdiev SI, Nishiyama Y, Takahashi S, Miyairi S, Suzuki I, Murata N. Systematic analysis of the relation of electron transport and ATP synthesis to the photodamage and repair of photosystem II in Synechocystis. Plant Physiol. 2005;137:263-73.

51. Cheirsilp B, Torpee S. Enhanced growth and lipid production of microalgae under mixotrophic culture condition: effect of light intensity, glucose concentration and fed-batch cultivation. Bioresour Technol. 2012;110:510-6.

52. Chen JJ, Li YU, Lai WL. Application of experimental design methodology for optimization of biofuel production for microalgae. Biomass Bioenergy. 2014;64:11-9.

53. Khalil Z, Asker MS, El-Sayed S, Kobbia I. Effect of pH on growth and biochemical responses of Dunaliella bardawil and Chlorella ellipsoidea. World J Microbiol Biotechnol. 2010;26:1225-31.

54. Kalita N, Baruah G, Goswami RCD, Talukdar J, Kalita MC. Ankistrodesmus falcatus: a promising candidate for lipid production, its biochemical analysis and strategies to enhance lipid productivity. J Microbiol Biotechnol Res. 2011;1:148.

55. Hu Q. Environmental effects on cell composition. In: Richmond A, editor Handbook of Microalgal Culture: Biotechnology and Applied Phycology. Oxford: Blackwell Science Ltd; 2004. p. 83-94.

56. Talebi AF, Tabatabaei M, Mohtashami SK, Thidfar M, Moradi F. Comparative salt stress study on intracellular ion concentration in Marine and salt-adapted freshwater strains of microalgae. Not Sci Biol. 2013;5:309-15.

57. Bondioli P, Della Bella L, Rivolta G, Chini Zittelli G, Bassi N, Rodolfi L, Casini D, Prussi M, Chiaramonti D, Tredici MR. Oil production by the marine microalgae Nannochloropsis sp. F\&M-M24 and Tetraselmis suecica F\&M-M33. Bioresour. Technol. 2012;114:567-72.

58. Hu Q, Sommerfeld M, Jarvis E, Ghirardi M, Posewitz M, Seibert M, et al. Microalgal triacylglycerols as feedstocks for biofuel production: perspectives and advances. Plant J. 2008:54:621-39.

59. Huerlimann R, de Nys R, Heimann K. Growth, lipid content, productivity, and fatty acid composition of tropical microalgae for scale-up production. Biotechnol Bioeng. 2010;107:245-57.

60. Rudolf A, Galbe M, Lidén G. Controlled fed-batch fermentation of dilute-acid hydrolisate in pilot development unit scale. Appl Biochem Biotechnol. 2004; 114:601-17

61. Cooper MS, Hardin WR, Petersen TW, Cattolico RA. Visualizing green oil in live algal cells. J Biosci Bioeng. 2010;109:198-201.

62. Silva TL, Roseiro JC, Reis A. Applications and perspectives of multi-parameter flow cytometry to microbial biofuels production processes. Trends Biotechnol. 2012;4:30.

63. Teo $\mathrm{CL}$, Jamaluddin $\mathrm{H}$, Mohd Zain NA, Idris A. Biodiesel production via lipase catalysed trans-esterification of microalgae lipids from Tetraselmis sp. Renew Energy. 2014;68:1-5.

64. Silva $T L$, Feijão D, Roseiro JC, Reis A. Monitoring Rhodotorula glutinis CCMI 145 physiological response and oil production growing on xylose and glucose using multi-parameter flow cytometry. Bioresour Technol. 2011;102:2998-3006.

65. Silva TL, Santos CA, Reis A. Multi-parameter flow cytometry as a tool to monitor heterotrophic microalgal batch fermentations for oil production towards biodiesel. Biotechnol Bioprocess Eng. 2009;14:330-7.

66. Silva TL, Feijao D, Reis A. Using multi-parameter flow cytometry to monitor the yeast Rhodotorula glutinis CCMI 145 batch growth and oil production towards biodiesel. Appl Biochem Biotechnol. 2010;162:2166-76.
67. Beardall J, Johnston A, Raven J. Environmental regulation of $\mathrm{CO}_{2}$-concentrating mechanisms in microalgae. Can J Bot. 1998;76:1010-7.

68. Harwood JL. Membrane lipids in algae. In: Siegenthaler PA, Murata N, editors. Lipids in Photosynthesis: Structure, Function and Genetics. Kluwer: Kluwer Academic Publishers; 1998.

69. Pereira H, Barreira L, Custódio L, Alrokayan S, Mouffouk F, Varela J, et al. Isolation and fatty acid profile of selected microalgae strains from the red sea for biofuel production. Energies. 2013;6:2773-83.

70. Selvakumar P, Umadevi K. Enhanced lipid and fatty acid content under photoheterotrophic condition in the mass cultures of Tetraselmis gracilis and Platymonas convolutae. Algal Res. 2014;6:180-5.

\section{Submit your next manuscript to BioMed Central and we will help you at every step:}

- We accept pre-submission inquiries

- Our selector tool helps you to find the most relevant journal

- We provide round the clock customer support

- Convenient online submission

- Thorough peer review

- Inclusion in PubMed and all major indexing services

- Maximum visibility for your research

Submit your manuscript at www.biomedcentral.com/submit
) Biomed Central 